\title{
Factors associated with the onset and remission of chronic daily headache in a population-based study
}

\author{
A.I. Scher ${ }^{\mathrm{a}, *}$, W.F. Stewart ${ }^{\mathrm{b}}$, J.A. Ricci ${ }^{\mathrm{c}}$, R.B. Lipton ${ }^{\mathrm{d}}$ \\ ${ }^{a}$ Laboratory of Epidemiology, Demography, and Biometry, National Institute on Aging, National Institutes of Health, Gateway Building, Suite 3C-309, \\ 7201 Wisconsin Avenue, MSC 9205, Bethesda, MD 20892-9205, USA \\ ${ }^{\mathrm{b}}$ Outcomes Research Institute, Geisinger Health Systems, Danville, PA, USA \\ ${ }^{\mathrm{c}}$ IMR, an AdvancePCS Company, Hunt Valley, MD, USA \\ ${ }^{\mathrm{d}}$ Department of Neurology, Epidemiology, and Population Health, Albert Einstein College of Medicine, Bronx, NY, USA
}

Received 2 May 2003; received in revised form 27 June 2003; accepted 9 July 2003

\begin{abstract}
The etiology and prognosis of chronic daily headache (CDH) are not well understood.

The aim of this study is to describe factors that predict $\mathrm{CDH}$ onset or remission in an adult population.

Potential cases $(180+$ headaches per year, $n=1134)$ and controls (two to 104 headaches per year, $n=798)$ were interviewed two times over an average 11 months of follow-up. Factors associated with $\mathrm{CDH}$ prevalence at baseline were evaluated. The incidence of CDH and risk factors for onset were assessed in controls whose headache frequency increased to $180+$ per year at follow-up. Prognostic factors were assessed in $\mathrm{CDH}$ cases whose headache frequency fell at follow-up.

$\mathrm{CDH}$ was more common in women, in whites, and those of less education. CDH cases were more likely to be previously married (divorced, widowed, separated), obese, and report a physician diagnosis of diabetes or arthritis.

At follow-up, $3 \%$ of the controls reported 180 or more headaches per year. Obesity and baseline headache frequency were significantly associated with new onset $\mathrm{CDH}$.

In $\mathrm{CDH}$ cases, the projected 1-year remission rate to less than one headache per week was $14 \%$ and to less than 180 headaches per year was $57 \%$. A better prognosis was associated with higher education, non-white race, being married, and with diagnosed diabetes.

Individuals with less than a high-school education, whites, and those who were previously married had a higher risk of $\mathrm{CDH}$ at baseline and reduced likelihood of remission at follow-up. New onset CDH was associated with baseline headache frequency and obesity.

(C) 2003 International Association for the Study of Pain. Published by Elsevier B.V. All rights reserved.
\end{abstract}

Keywords: Chronic daily headache; Incidence; Remission; Prognosis; Epidemiology

\section{Introduction}

About $4 \%$ of the adult population experiences headache 15 days per month or more (chronic daily headache) (Scher et al., 1998; Castillo et al., 1999; Wang et al., 2000; Hagen et al., 2000; Prencipe et al., 2001; Lu et al., 2001; Lanteri-Minet et al., 2003). The two most prevalent types of primary chronic daily headache $(\mathrm{CDH})$, equally represented in population samples, are chronic tension-type headache and chronic migraine (also known as transformed migraine) (Scher et al., 1998; Castillo et al., 1999; Wang

\footnotetext{
* Corresponding author. Tel.: + 1-301-496-6443; fax: + 1-301-496-4006.

E-mail addresses: schera@mail.nih.gov (A.I. Scher), rlipton@aecom. yu.edu (R.B. Lipton).
}

et al., 2000; Prencipe et al., 2001; Lu et al., 2001). Although the etiology of $\mathrm{CDH}$ is uncertain, demographic risk factors identified in earlier studies include female gender and lower educational level.

There are limited data on the natural course of $\mathrm{CDH}$ in clinical or population samples although there are a number of studies describing the efficacy of various inpatient and outpatient regimens for CDH (Baumgartner et al., 1989; Lake et al., 1993; Pini et al., 1996; Schnider et al., 1996; Pringsheim and Howse, 1998; Zed et al., 1999; Krymchantowski and Barbosa, 2000; Linton-Dahlof et al., 2000; Lu et al., 2000). With aggressive treatment, including inpatient medication withdrawal and other interventions, about half of $\mathrm{CDH}$ patients in specialty care remit to less than 15 headaches days per month. 
There are some prognostic data for $\mathrm{CDH}$ from three population studies. In one study based on a Chinese elderly population (average age 74), individuals were interviewed three times over a 4-year period (Wang et al., 2000). In this series, approximately one-third of $\mathrm{CDH}$ cases had remitted to less than 15 headaches per month at the follow-up interviews. Only about $15 \%$ had remitted to less than one headache per week. In a Taiwanese study, $65 \%$ of the $\mathrm{CDH}$ sufferers had remitted to less than 15 headaches per month at a 2-year follow-up (Lu et al., 2001). A third study looked at $\mathrm{CDH}$ incidence in an adult population thought unlikely to have headache based on their non-use of analgesics (Hagen et al., 2002b). The authors found that low socioeconomic status at baseline predicted having $\mathrm{CDH}$ at follow-up approximately 11 years later.

The aims of this study are to identify risk factors for $\mathrm{CDH}$ prevalence, incidence, and remission in a US adult population. Participants were interviewed twice with an average of 11 months between baseline and follow-up. Factors predicting a better or worse prognosis at follow-up are described. Ultimately, the identification of individuals at higher risk of headache acceleration might improve the clinical management of $\mathrm{CDH}$.

\section{Methods}

\subsection{Overview}

We conducted a study to evaluate factors associated with prevalent, new-onset, and remitted cases of $\mathrm{CDH}$. Data were collected during two telephone interviews approximately 11 months apart using a computer-assisted telephone interview. Baseline headache frequency was used to define a $\mathrm{CDH}$ case group and an episodic headache control group. Data on headache frequency collected during the follow-up interview was used to identify $\mathrm{CDH}$ cases whose headache frequency declined (remitted $\mathrm{CDH}$ cases) and controls with an increased headache frequency (new-onset/incident $\mathrm{CDH}$ cases). Factors associated with prevalent $\mathrm{CDH}$, new-onset $\mathrm{CDH}$, and remitted $\mathrm{CDH}$ were based on comparisons between: (a) baseline CDH cases and controls; (b) baseline controls and new-onset $\mathrm{CDH}$ cases; and (c) baseline $\mathrm{CDH}$ cases and remitted $\mathrm{CDH}$ cases.

\subsection{Sample}

Potential CDH cases and controls were selected from participants in community telephone health surveys conducted in the Baltimore, Philadelphia, and Atlanta metropolitan areas between November 1997 and December 1999. The baseline survey was conducted to identify individuals with selected health conditions who might be eligible for clinical trials. Baseline survey participants were between the ages of 18 and 65 and were required to speak English.

\subsection{Case definition}

Selection of baseline survey participants for a follow-up survey was limited to those who reported either their first name or initial, or both their gender and date of birth to ensure accurate identification. Two groups were selected based on their annual baseline headache frequency: cases with chronic daily headache (180 or more headaches per year) and controls (two to 104 headaches per year). A broad range of headache frequency was used to define controls so that baseline headache frequency itself could be evaluated as an independent risk factor for new-onset $\mathrm{CDH}$.

A total of 55,255 potential cases and controls participated in the baseline survey. At follow-up, efforts were made to contact potential cases and controls defined by their baseline status. Follow-up telephone interviews were conducted from December 1999 to February 2000. Control interviews were completed 1 month before all case interviews were completed. Up to ten attempts were made to contact each of the $\mathrm{CDH}$ cases $(n=2599)$ and a random sample of approximately $4 \%$ of the controls $(n=2033)$.

Recruitment results are summarized in Table 1. Approximately half of the candidate $\mathrm{CDH}$ cases (49\%) and controls (51\%) could not be reached at follow-up for a number of reasons including their phone number was no longer valid, they no longer lived at the same number, they were deceased, or more than ten unsuccessful attempts were made to reach the number. An additional $10 \%$ of controls and $7 \%$ of cases either refused participation or were not eligible due to age, incompatible schedule, or mental status. Of the remainder, 798 controls and 1134 cases were able to provide their current headache frequency in headache days per year ${ }^{1}$. Because the study quota was filled more rapidly for the controls than cases, the elapsed time between baseline and follow-up interviews was about 2 months longer for controls than cases (354 versus 287 days, $P<0.001)$.

\subsection{Data collection}

Information collected during the baseline interview included gender, age, height (inches), weight (pounds), current marital status (married, widowed, divorced, separated, or never married), highest educational level $(<$ high school graduate, high school graduate, some college, college graduate, graduate school), and race (white, nonwhite). Body-mass index (BMI) was calculated as (703* weight)/(height $*$ height $)$ and categorized as normal $(<25)$, overweight $(25-<30)$, and obese $(30+)$. Marital status categories were combined as follows: currently married, previously married (e.g. widowed divorced or separated), and never married. Participants were also asked

\footnotetext{
${ }^{1}$ Because of wording differences in the baseline and follow-up survey, baseline headache frequency refers to headaches per year while follow-up frequency refers to headache days per year.
} 
Table 1

Disposition of potential cases and controls

\begin{tabular}{lrrrr}
\hline & Controls & $\%$ & Cases & $\%$ \\
\hline $\begin{array}{l}\text { Identified from baseline interview } \\
\text { No longer at number }\end{array}$ & 2033 & 100 & 2599 & 100 \\
or deceased & 359 & 18 & 379 & 15 \\
Non-working number, fax, business, & 667 & 33 & 437 & 17 \\
etc. & & & & \\
Closed out after ten & 0 & 0 & 447 & 17 \\
attempts & & & & \\
Total contacted & 1007 & 49 & 1336 & 51 \\
& 1007 & 100 & 1336 & 100 \\
Reached at follow-up & 165 & 16 & 102 & 8 \\
Refused & 31 & 3 & 75 & 6 \\
NE age/mental status/schedule & 8 & 1 & 18 & 1 \\
Missing/refused/invalid headache data & 798 & 39 & 1134 & 44 \\
Analytic sample & & & & \\
& $798 / 2003$ & 39 & $1134 / 2599$ & 44 \\
Participation among total & $798 / 1007$ & 79 & $1134 / 1336$ & 85 \\
Participation among contacted & & & & \\
\hline
\end{tabular}

${ }^{a}$ The quota for controls was reached before it was necessary to close out any potential controls. The study terminated when all potential cases were either contacted or called at least ten times.

if they had ever been diagnosed as having arthritis (for those age 40 or older) or diabetes.

At follow-up, the baseline $\mathrm{CDH}$ cases were interviewed about their headache history. Questions were asked about duration of $\mathrm{CDH}$, pre-CDH headache frequency, and the speed of onset of CDH (over less than a week, less than a month, more than a month). Cases who had remitted by follow-up were also asked about the speed of resolution (over less than a week, less than a month, more than a month). In addition, cases with daily headache at follow-up were asked if their headaches were continuous (i.e. headache 'all day, every day, morning to night').

The telephone interview also focused on risk factors during the time period that $\mathrm{CDH}$ developed and an equivalent time period in the controls. These results will be reported separately.

\subsection{Analysis}

Analyzes were limited to the sub-group of cases $(n=1134)$ and controls $(n=798)$ who were interviewed at follow-up and who were able to answer the question about headache frequency. Factors associated with prevalent $\mathrm{CDH}$ were evaluated by comparing these cases to controls. Factors associated with new onset of $\mathrm{CDH}$ (i.e. incident cases) were evaluated by comparing new onset $\mathrm{CDH}$ cases (two to 104 headaches at baseline and $180+$ headaches at follow-up) to stable controls (two to 104 headaches at both interviews). Similarly, factors associated with headache remission were evaluated by comparing remitted $\mathrm{CDH}$ cases $(180+$ headaches at baseline, $<52$ headaches at follow-up) to stable $\mathrm{CDH}$ cases $(180+$ headaches at both interviews).

Multiple logistic regression (Intercooled Stata 7.0) was used to estimate the odds ratios for the association between $\mathrm{CDH}$ status (i.e. prevalent, new-onset, and remitted $\mathrm{CDH}$ ) and demographic (age, gender, education, marital status, race) and other factors (BMI, arthritis, diabetes, baseline headache frequency, and elapsed time between interviews).

Multivariate logistic regression was used to estimate the odds ratio for each explanatory variable while simultaneously adjusting for potential confounders of the relationship between the explanatory variable and $\mathrm{CDH}$ prevalence, remission, or onset. Continuous independent variables were evaluated for non-linearity using squared and higher order terms. Backwards stepwise maximum-likelihood estimation (Stata command sw) was used to arrive at a parsimonious model. Explanatory variables with a $P$-value $>0.05$ (Wald test) were considered for exclusion from the model. The study design was approved by the Institutional Review Board of the Johns Hopkins School of Public Health.

\section{Results}

Tables 2-4 describe factors associated with $\mathrm{CDH}$ prevalence (Table 2), new-onset (Table 3), and remission (Table 4).

\subsection{Prevalence}

In univariate analysis (Table $2-\mathrm{OR} A$ ), $\mathrm{CDH}$ prevalence decreased slightly with age $(P<0.05)$ and was more common in women $(\mathrm{OR}=1.65[1.3-2.0])$ and previously married (e.g. divorced or widowed or separated) individuals $(\mathrm{OR}=1.50[1.2-1.9])$. $\mathrm{CDH}$ prevalence was inversely associated with educational level. Having less than a high-school education was associated with more than a 3-fold risk of $\mathrm{CDH}$ compared to those with a graduate school-level education ( $\mathrm{OR}=3.56$ [2.3-5.6]). $\mathrm{CDH}$ was also associated with a self-reported physician diagnosis of arthritis $(\mathrm{OR}=2.50[1.9-3.3])$ or diabetes $(\mathrm{OR}=1.51$ [1.01-2.3]).

ORs did not vary substantially after adjusting for potential confounders. Moreover, two associations (reduced risk in non-whites and increased risk with obesity) were strengthened and reached marginal statistical significance (Table 2 - OR B).

\subsection{New onset of $\mathrm{CDH}$}

At the time of the follow-up survey, 91\% $(n=726)$ of the controls continued to meet criteria as a control (i.e. $<=104$ headaches per year), $6 \%(n=49)$ had progressed to an intermediate headache frequency (i.e. 105-179 headaches per year) and 3\% $(n=23)$ met $\mathrm{CDH}$ criteria (i.e. $180+$ headaches per year). 
Table 2

Characteristics associated with prevalent $\mathrm{CDH}^{\mathrm{a}}$

\begin{tabular}{|c|c|c|c|c|c|}
\hline & & $\begin{array}{l}\text { Controls } \\
(n=1134 ; \%)\end{array}$ & $\begin{array}{l}\text { Cases } \\
(n=798 ; \%)\end{array}$ & Crude (OR A) & Adjusted (OR B $\left.{ }^{\mathrm{b}}\right)$ \\
\hline \multirow[t]{2}{*}{ Gender } & Male & 28 & 20 & 1.00 & 1.00 \\
\hline & Female & 71 & 80 & $1.65[1.3-2.0]^{* *}$ & $1.69[1.4-2.1]^{* *}$ \\
\hline Age & Mean age & 41 & 40 & $0.99[0.98-1.00]^{*}$ & $0.98[0.98-0.99]^{* *}$ \\
\hline \multirow[t]{3}{*}{ Race } & Caucasian & 71 & 73 & 1.00 & 1.00 \\
\hline & Non-caucasian & 27 & 25 & $0.93[0.8-1.1]$ & $0.77[0.6-1.0]^{*}$ \\
\hline & Missing/refused & 3 & 2 & $0.72[0.4-1.3]$ & $0.82[0.4-1.6]$ \\
\hline \multirow[t]{4}{*}{ BMI } & Normal $(<25)$ & 31 & 31 & 1.00 & 1.00 \\
\hline & Overweight & 19 & 21 & $1.08[0.8-1.4]$ & $1.26[1.0-1.7]$ \\
\hline & Obese $(>=30)$ & 14 & 18 & $1.27[1.0-1.7]$ & $1.34[1.0-1.8]^{*}$ \\
\hline & Missing/refused & 35 & 30 & $0.84[0.7-1.1]$ & $0.84[0.7-1.1]$ \\
\hline \multirow[t]{6}{*}{ Education } & $<\mathrm{HS}$ & 4 & 11 & $3.56[2.3-5.6]^{* *}$ & $3.35[2.1-5.3]^{* *}$ \\
\hline & HS & 29 & 34 & $1.62[1.2-2.2]^{* *}$ & $1.49[1.1-2.0]^{*}$ \\
\hline & Some college & 27 & 24 & $1.25[0.9-1.7]$ & $1.16[0.8-1.6]$ \\
\hline & College & 25 & 20 & $1.08[08-1.5]$ & $1.10[0.8-1.5]$ \\
\hline & Grad & 15 & 11 & 1.00 & 1.00 \\
\hline & Missing/ref & 1 & $<1$ & $0.97[0.2-4.0]$ & $1.93[0.4-9.5]$ \\
\hline Current & Married & 56 & 52 & 1.00 & 1.00 \\
\hline Marital & Previously married $^{\mathrm{c}}$ & 15 & 21 & $1.50[1.2-1.9]^{* *}$ & $1.45[1.1-1.9]^{*}$ \\
\hline \multirow[t]{2}{*}{ Status } & Never married & 23 & 24 & $1.13[0.9-1.4]$ & $1.05[0.8-1.4]$ \\
\hline & Missing/ref & 6 & 3 & $0.49[0.3-0.8]^{* *}$ & $0.48[0.3-0.8]^{* *}$ \\
\hline Dx arthritis & No & 69 & 53 & 1.00 & 1.00 \\
\hline \multirow[t]{2}{*}{$($ age $>=40)$} & Yes & 22 & 43 & $2.50[1.9-3.3]^{* *}$ & $2.41[1.8-3.3]^{* *}$ \\
\hline & Missing/ref & 8 & 4 & $0.66[0.4-1.1]$ & $5.26[0.6-47.0]$ \\
\hline Dx diabetes & Missing/ref & 7 & 4 & $0.59[0.4-0.9]^{*}$ & $1.99[0.9-4.6]$ \\
\hline
\end{tabular}

${ }^{\text {a }}$ Note: Comparing baseline $\mathrm{CDH}$ cases $(n=1134)$ to baseline controls $(n=798) * P<0.05$; and $* * P<0.005$.

b Adjusted for age, gender, marital status, race, educational level, body-mass index.

c Previously married includes widowed or divorced or separated.

Elapsed time between interviews was not significantly associated with new-onset $\mathrm{CDH}(\mathrm{OR}=1.03$ per month, $P=0.274)$. The risk of new-onset $\mathrm{CDH}$ increased nonlinearly with baseline headache frequency $(P<0.005)$; elevated risk was primarily limited to controls with more than about two headaches per month (Fig. 1).

In other univariate comparisons (Table 3 - OR C), $\mathrm{CDH}$ onset was significantly associated with obesity $(\mathrm{OR}=5.53$, [1.4-21.8]) and self-reported physician diagnosed arthritis $(\mathrm{OR}=3.29,[1.03-10.5])$. It was also associated with selfreported physician diagnosed diabetes although this finding did not reach statistical significance $(\mathrm{OR}=3.43$, [0.9612.3], $P=0.059)$. After adjusting for BMI and baseline headache frequency, associations between new-onset $\mathrm{CDH}$ and both diabetes $(\mathrm{OR}=3.00, P=0.113)$ and arthritis $(\mathrm{OR}=2.52, P=0.142)$ were attenuated and lost significance (Table 3 - OR D).

\section{3. $\mathrm{CDH}$ remission}

Of the CDH cases contacted at follow-up, 44\% $(n=495)$ still reported 180 or more headaches per year, $43 \%$ reported an intermediate headache frequency $(52-179$ headaches per year), and $13 \%(n=153)$ reported fewer than 52 headaches per year. (The corresponding figures projected to 1 year are 42, 43, and 14\%).

Remission to less than one headache per week was positively associated with the elapsed time between interviews $(\mathrm{OR}=1.05$ per month, $P<0.005)$ and was weakly negatively associated with baseline headache frequency $(P<0.05)$ (Fig. 2). In other univariate comparisons (Table 4 - OR E), being previously married was associated with a reduced rate of remission $(\mathrm{OR}=0.59$ [0.4-1.0], $P=0.05)$ while having a history of diagnosed diabetes $(\mathrm{OR}=2.66[1.4-5.1])$ was positively associated with 
Table 3

Characteristics associated with incident $\mathrm{CDH}^{\mathrm{a}}$

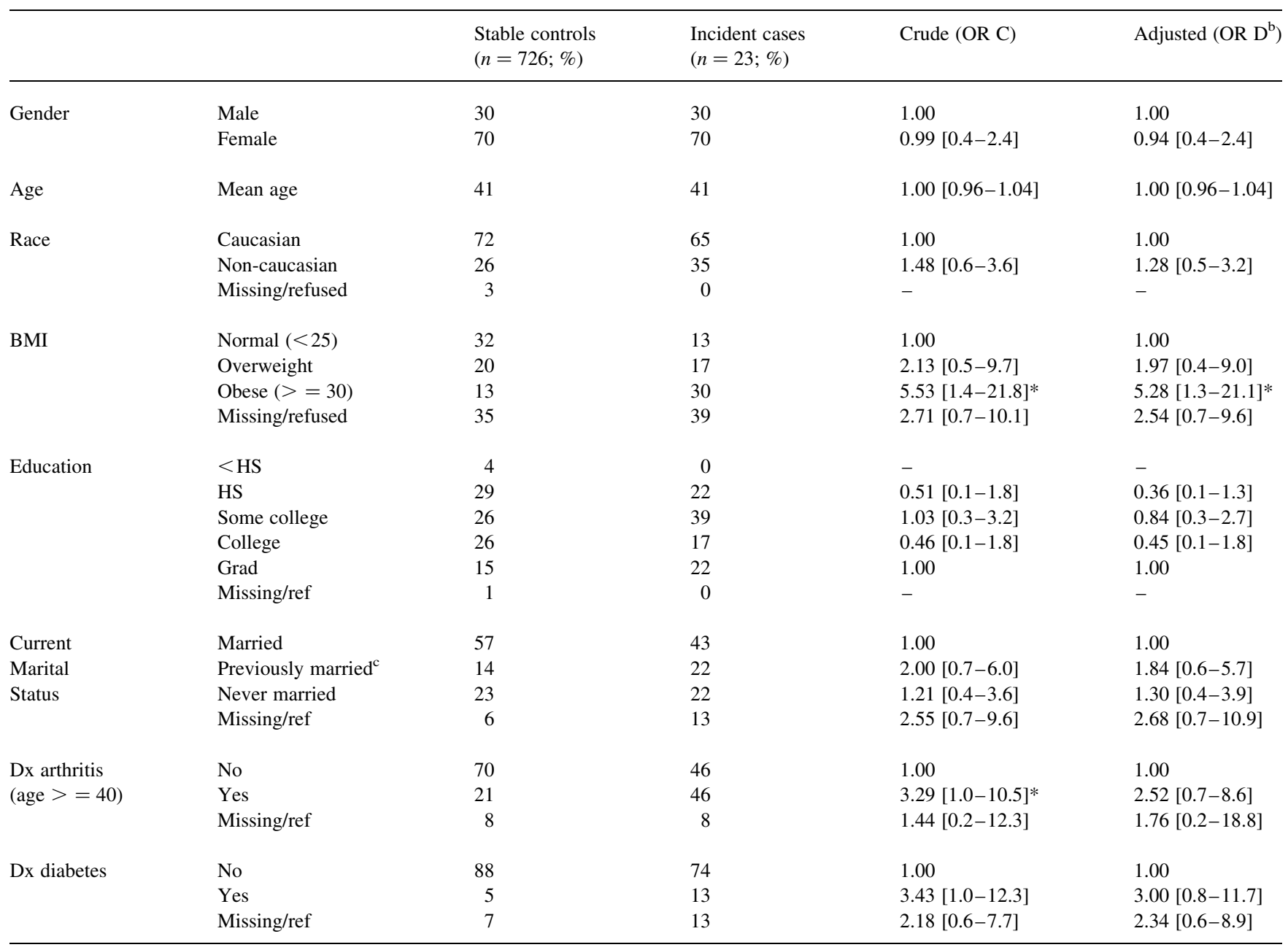

a Note: Among controls, comparing new-onset cases $(n=23)$ to stable controls $(n=726) * P<0.05$.

b Adjusted for BMI and baseline headache frequency-squared.

c Previously married includes widowed or divorced or separated.

remission. Remission was positively associated with increased educational level. In particular, the odds of remission were substantially lower for those with less than a high-school education $(\mathrm{OR}=0.21[0.1-0.5])$ compared to those with graduate school-level education. There was an interaction between gender and age, with remission more likely to occur with increasing age in women but not men $(P<0.005)$.

Results did not change substantially in multivariate models (Table 4 - OR F), with one exception. The odds ratio for remission and non-white race increased and became statistically significant $(\mathrm{OR}=2.05[1.3-3.2])$.

\section{4. $C D H$ history}

Data collected on CDH history were captured during the follow-up interview. $\mathrm{CDH}$ cases varied in their reported speed of onset, with $29 \%$ reporting acute onset (i.e. occurred within 1 week), $8 \%$ reporting onset in more than 1 week but less than 1 month, and the majority (63\%) reporting more gradual onset. Reported speed of onset did not appear to vary by $\mathrm{CDH}$ status (i.e. persistence vs. remission at followup). For those who had remitted at the follow-up interview, the speed of remission was usually gradual (68\%), with only $20 \%$ reporting remission over less than a week.

The data in Table 5 are based on the 495 baseline CDH cases who still reported $180+$ headaches per year at follow-up. The average age of all $\mathrm{CDH}$ cases was 41 years, although those with 'continuous headache' were about 3 years older (Table 5). Reported $\mathrm{CDH}$ duration was 7 years (median 4), with longer duration in the continuous $\mathrm{CDH}$ sub-group. A total of $28 \%$ of $\mathrm{CDH}$ cases (and $39 \%$ of those with continuous headache) reported duration of 10 or more years. Age at onset was calculated by subtracting duration from age at follow-up. The average age at onset was 33.5 years and did not differ significantly by case subgroup.

Prior to the onset of their current headache frequency, the average headache frequency was 90 headaches per year 
Table 4

Characteristics associated with remitted $\mathrm{CDH}^{\mathrm{a}}$

\begin{tabular}{|c|c|c|c|c|c|}
\hline & & $\begin{array}{l}\text { Stable cases } \\
(n=495 ; \%)\end{array}$ & $\begin{array}{l}\text { Remitted cases } \\
(n=153 ; \%)\end{array}$ & Crude (OR E) & Adjusted $\left(\mathrm{OR} \mathrm{F}^{\mathrm{b}}\right)$ \\
\hline \multirow[t]{2}{*}{ Gender } & Male & 27 & 23 & 1.00 & \\
\hline & Female & 73 & 77 & $0.80[0.5-1.2]$ & \\
\hline \multirow[t]{2}{*}{ Age } & Mean age & 40 & 41 & $1.01[0.99-1.02]$ & \\
\hline & Female $\times$ age & & & & $1.04[1.01-1.06]^{* *}$ \\
\hline \multirow[t]{3}{*}{ Race } & Caucasian & 76 & 68 & 1.00 & 1.00 \\
\hline & Non-caucasian & 22 & 29 & $1.48[1.0-2.2]$ & $2.05[1.3-3.2]^{* * *}$ \\
\hline & Missing/refused & 2 & 3 & $1.61[0.5-5.3]$ & $1.25[0.3-4.7]$ \\
\hline \multirow[t]{3}{*}{ BMI } & Normal $(<25)$ & 33 & 24 & 1.00 & 1.00 \\
\hline & Overweight & 21 & 25 & $1.66[1.0-2.8]^{*}$ & $1.49[0.9-2.6]$ \\
\hline & Missing/refused & 28 & 30 & $1.46[0.9-2.4]$ & $0.89[0.5-1.6]$ \\
\hline \multirow[t]{6}{*}{ Education } & $<\mathrm{HS}$ & 14 & 5 & $0.21[0.1-0.5]^{* *}$ & $0.21[0.1-0.5]^{* *}$ \\
\hline & HS & 36 & 33 & $0.52[0.3-1.0]^{*}$ & $0.57[0.3-1.1]$ \\
\hline & Some college & 21 & 26 & $0.70[0.4-1.3]$ & $0.72[0.4-1.4]$ \\
\hline & College & 20 & 22 & $0.64[0.3-1.2]$ & $0.63[0.3-1.2]$ \\
\hline & Grad & 8 & 14 & 1.00 & 1.00 \\
\hline & Missing/ref & $<1$ & 0 & - & - \\
\hline Current & Married & 52 & 57 & 1.00 & 1.00 \\
\hline Marital & Previously married $^{\mathrm{c}}$ & 22 & 14 & $0.59[0.4-1.0]^{*}$ & $0.51[0.3-0.9]^{*}$ \\
\hline \multirow[t]{2}{*}{ Status } & Never married & 24 & 24 & $0.92[0.6-1.4]$ & $0.99[0.6-1.6]$ \\
\hline & Missing/ref & 3 & 5 & $1.36[0.5-3.5]$ & $0.42[0.1-1.3]$ \\
\hline \multirow{2}{*}{$\begin{array}{l}\text { Dx arthritis } \\
(\text { age }>=40)\end{array}$} & No & 51 & 52 & 1.00 & 1.00 \\
\hline & Yes & 44 & 42 & $0.95[0.6-1.6]$ & $1.04[0.6-1.8]$ \\
\hline \multirow[t]{3}{*}{ Dx diabetes } & No & 91 & 83 & 1.00 & 1.00 \\
\hline & Yes & 5 & 12 & $2.66[1.4-5.1]^{* *}$ & $2.70[1.3-5.5]^{*}$ \\
\hline & Missing/ref & 4 & 5 & $1.42[0.6-3.3]$ & $0.29[0.03-2.8]$ \\
\hline
\end{tabular}

${ }^{\text {a }}$ Note: Among CDH cases, comparing cases who remitted to $<1$ headache/week $(n=153)$ to stable cases $(n=495) * P<0.05$; and $* * P<0.005$.

b Adjusted for gender, age $\times$ female-gender, marital status, educational level, race, elapsed time between interviews, and baseline headache frequency (frequency and frequency-squared).

c Previously married includes widowed or divorced or separated.

(median 52). Pre-CDH headache frequency was lower in the sudden-onset cases compared to the entire case group $(P<0.05$ rank-sum test $)$.

\section{Discussion}

This longitudinal study demonstrates that in the population, $\mathrm{CDH}$ sufferers constitute a dynamic case pool characterized by the onset and remission of high frequency headache. While the projected 1-year remission rate to less than 180 headaches per year was high (57\%), remission to the more 'normal' headache frequency of less than one headache per week was uncommon (14\%). Our estimated remission rate is similar to that observed in a previous population-based study from Taiwan $(65 \%$ remitted to fewer than 15 headaches per month after 2 years) (Lu et al., 2001), but considerably higher than that observed in a Chinese elderly population (33\% had remitted over a 4-year period) (Wang et al., 2000).

It is noteworthy that $\mathrm{CDH}$ remission (i.e. to a headache rate of less than 15 days/month) in clinic samples in response to medication-withdrawal and other treatments is roughly similar to the rate observed in our study (Zed et al., 1999; Scher et al., 2002). Of course, CDH patients who seek specialty care are likely to differ from CDH sufferers in the population. For example, $\mathrm{CDH}$ patients in subspecialty centers are more likely to have migraine headaches and exceed limits on recommended use of analgesics/ergot than $\mathrm{CDH}$ sufferers in less selected populations (Scher et al., 2002). Nonetheless, the finding that a significant proportion of $\mathrm{CDH}$ sufferers in the population remit (presumably) in 


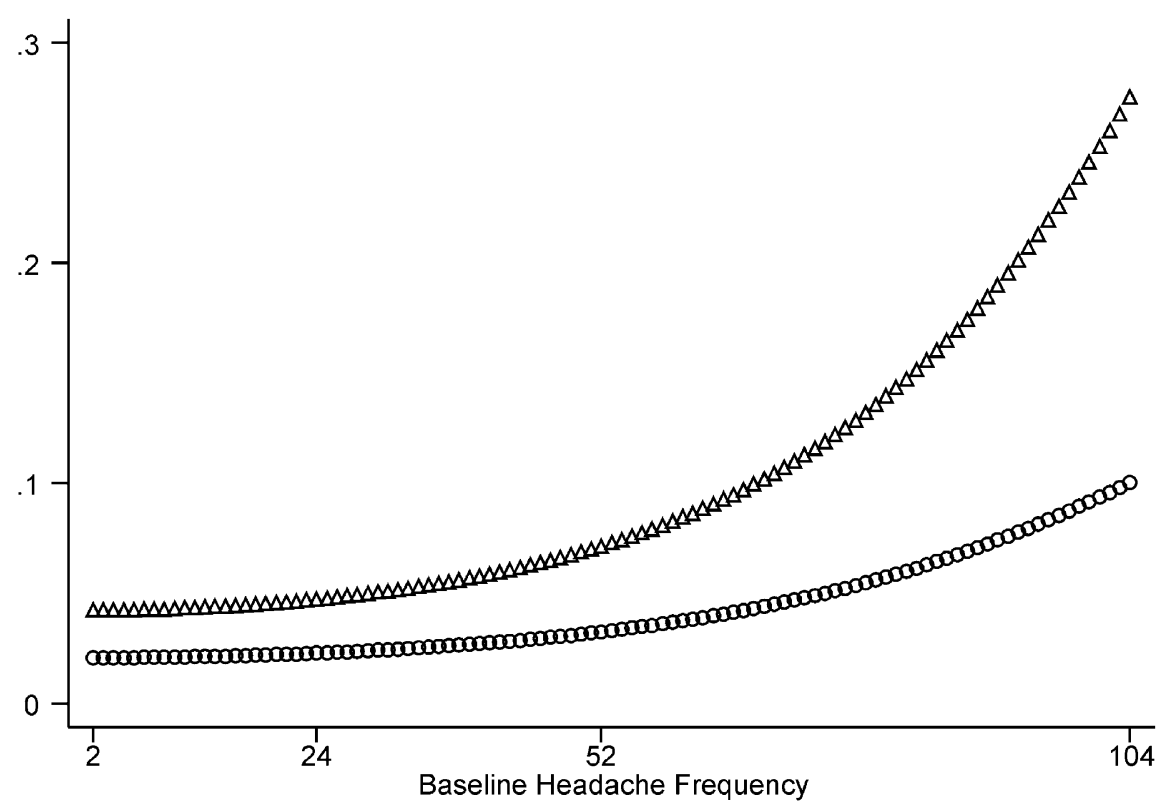

Fig. 1. Estimated 1-year incidence rate of: (a) chronic daily headache (180 + headaches/year); or (b) increased headaches (105-179) in an episodic headache population by baseline headache frequency. Note for Fig. 1: predictions are calculated using multinomial logistic regression and are adjusted for baseline headache frequency and elapsed time between interviews. Fig. 1 shows predicted 1-year incidence.

the absence of headache-specific treatment, underscores the need for controlled trials of medication withdrawal as a treatment for chronic daily headache.

Demographic factors associated with an increased risk of $\mathrm{CDH}$ include female gender, white race, lower educational level, and being previously married (e.g. divorced or widowed or separated). These demographic factors showed a similar directional association with remission, as remission was more likely in non-whites, individuals with more education, and the currently married. A similar negative

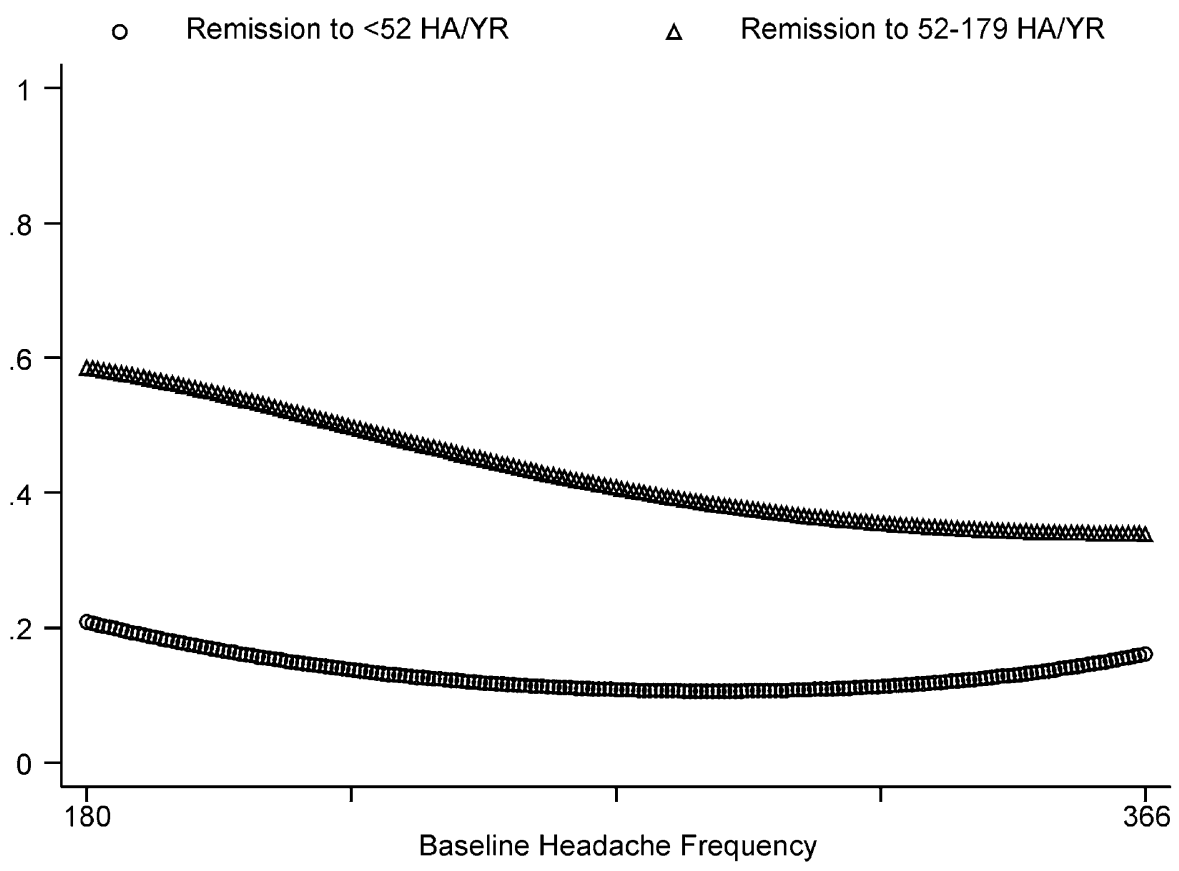

Fig. 2. Estimated 1-year remission rate to: (a) less than one headache per week; and (b) less than 180 headaches per year by baseline headache frequency. Note for Fig. 2: predictions are calculated using multinomial logistic regression and are adjusted for baseline headache frequency and elapsed time between interviews. Fig. 2 shows predicted 1-year remission. 
Table 5

Headache history in CDH cases overall and by sub-groups

\begin{tabular}{|c|c|c|c|c|c|}
\hline & \multicolumn{4}{|c|}{ Case sub-groups (not mutually exclusive) } & \multirow[t]{2}{*}{ Total $(n=495)$} \\
\hline & 'Continuous' $(n=81)$ & 'Sudden' $(n=164)$ & Male $(n=95)$ & Female $(n=399)$ & \\
\hline Average (median) HA frequency at interview 2 & $364(364) * *$ & $269(260)^{*}$ & $287(260)$ & $276(260)$ & $278(260)$ \\
\hline Average (median) HA frequency at interview 1 & $328(364)^{* *}$ & $286(260)$ & $293(260)$ & $289(260)$ & $290(260)$ \\
\hline Average (median) pre-CDH HA frequency & $104(104)$ & $76(52)^{*}$ & $81(52)$ & $92(52)$ & $90(52)$ \\
\hline Average (median) age at interview 2 & $43.6(44)^{*}$ & $40.0(40)$ & $42.6(40)$ & $40.5(40)$ & $40.9(40)$ \\
\hline Duration $10+$ years $(\%)$ & $39 *$ & 30 & 31 & 28 & 28 \\
\hline Average (median) age at onset of $\mathrm{CDH}$ & $34.3(35.5)$ & $32.1(31.5)$ & $35.5(37)$ & $33.0(33)$ & $33.5(34)$ \\
\hline
\end{tabular}

Continuous cases: have a headache 'all day, every day, morning to night' Sudden cases: CDH onset over a month or less; pre-CDH headache frequency: 'how many headaches did you use to get before they became very frequent?'. ${ }^{*} P<0.05$; $* * P<0.005$ compared to the total case group, Wilcoxon rank-sum test.

effect of lower socioeconomic status on headache prognosis was shown in the earlier study from Norway (Hagen et al., 2002b).

The natural history of CDH may differ by sex as the likelihood of remission increased with age for women but not men. The effect of migraine, which is more prevalent in women and tends to remit with age more than tension-type headache, may play a role in the gender-specific prognostic difference. As we did not have data on headache type at baseline, we could not test this hypothesis.

Two medical diagnoses assessed at baseline (arthritis, and diabetes) were more likely in the $\mathrm{CDH}$ cases than controls. Curiously, diagnosed diabetes also was associated with a better prognosis at follow-up. Obesity also tended to be associated with prevalent $\mathrm{CDH}$ and was a predictor of incident $\mathrm{CDH}$ at follow-up. The association of arthritis with $\mathrm{CDH}$ is consistent with other reports showing that chronic pain conditions tend to co-occur (Aaron and Buchwald, 2001; Hagen et al., 2002a).

The 1-year incidence of new-onset $\mathrm{CDH}$ was surprisingly high at $3 \%$ in this longitudinal study. Some risk factors were associated with incidence of $\mathrm{CDH}$, although analyzes were limited by the small number of incident cases. We found that control subjects with higher headache frequency were more likely to have incident $\mathrm{CDH}$ at follow-up. This is somewhat tautologic, as controls with a higher baseline headache frequency more easily reach the $180+$ headache per year cut-off than controls with fewer headaches. Nonetheless, the risk of incident CDH associated with headache frequency was primarily observed in controls with more than about two headaches per month; in this group clinical vigilance to prevent progression may be important.

We found that obesity, defined by a BMI of 30 or greater, was a risk factor for the development of $\mathrm{CDH}$. The mechanisms here are not clear. Obesity is associated with the metabolic syndrome of aging, a pro-inflammatory, prothrombotic state which may contribute to headache progression (Hansen, 1999). If causal, weight loss in obese individuals with a high baseline frequency of headache may decrease the probability of progression, though specifically designed studies are required to test this hypothesis.

A minority of the $\mathrm{CDH}$ sufferers (16\%) reported 'continuous' headaches. These individuals are older and have had $\mathrm{CDH}$ for more years than the non-continuous cases. Thus, if there is such a thing as a progressive headache syndrome, continuous headache may represent a later stage of the disorder.

\subsection{Limitations}

One potential limitation of this study is that a significant proportion of the potential cases and controls could not be reached at follow-up. We were concerned about selective participation in the follow-up interview. Using baseline data, we found no difference in headache frequency between the cases/controls who were reached and those who were not. Furthermore, loss to follow-up was not differential between cases and controls by demographic factors (educational level, gender, age, race, and marital status). That is, while loss to follow-up was more likely for men, younger individuals, non-whites, and unmarried individuals, the rate of attrition was similar for the cases and controls. Therefore, we do not believe that loss to follow-up substantially affected the results reported herein.

Because of wording differences in the two surveys, headache frequency at baseline was defined in terms of headaches per year while headache frequency at follow-up was defined as headache days per year. It is difficult to estimate the net effect this might have had on case classification as both overestimates of $\mathrm{CDH}$ prevalence are possible (e.g. misclassifying as a case an individual with 100 days of numerous short-lasting cluster attacks) and underestimates of $\mathrm{CDH}$ prevalence are possible (e.g. misclassifying as a control an individual with 100 headaches per year where each attack spanned 2 days). However, such situations are likely to be rare in the general population.

Cases and controls were selected from participants in a general health survey that did not focus specifically on 
headache. Thus, baseline information was not available on headache characteristics or medication use, both of which might be prognostic factors. However, these data were collected at follow-up and will be reported on separately.

In summary, we found chronic daily headache to be more prevalent in women, individuals with less education, whites, and those who were previously married. $\mathrm{CDH}$ prevalence was associated with obesity and two obesity-related conditions, arthritis and diabetes. Many of these factors were similarly associated with prognosis at an average of 1 year of follow-up. Individuals with continuous daily headache may represent a later stage of $\mathrm{CDH}$.

\section{Acknowledgements}

The authors acknowledge the financial support of GlaxoSmithKline, the Migraine Trust, and the American Headache Society

\section{References}

Aaron LA, Buchwald D. A review of the evidence for overlap among unexplained clinical conditions. Ann Intern Med 2001;134:868-81.

Baumgartner C, Wessely P, Bingol C, Maly J, Holzner F. Longterm prognosis of analgesic withdrawal in patients with drug-induced headaches. Headache 1989;29:510-4.

Castillo J, Munoz P, Guitera V, Pascual J. Kaplan Award 1998: epidemiology of chronic daily headache in the general population. Headache 1999;39:190-6.

Hagen K, Zwart JA, Vatten L, Stovner LJ, Bovim G. Prevalence of migraine and non-migrainous headache - head-HUNT, a large population-based study. Cephalalgia 2000;20:900-6.

Hagen K, Einarsen C, Zwart JA, Svebak S, Bovim G. The co-occurrence of headache and musculoskeletal symptoms amongst 51,050 adults in Norway. Eur J Neurol 2002a;9:527-33.

Hagen K, Vatten L, Stovner LJ, Zwart JA, Krokstad S, Bovim G. Low socio-economic status is associated with increased risk of frequent headache: a prospective study of 22,718 adults in Norway. Cephalalgia $2002 b ; 22: 672-9$.
Hansen BC. The metabolic syndrome X. Ann N Y Acad Sci 1999;892: $1-24$.

Krymchantowski AV, Barbosa JS. Prednisone as initial treatment of analgesic-induced daily headache. Cephalalgia 2000;20:107-13.

Lake AE, Saper JR, Madden SF, Kreeger C. Comprehensive inpatient treatment for intractable migraine: a prospective long-term outcome study. Headache 1993;33:55-62.

Lanteri-Minet M, Auray JP, El Hasnaoui A, Dartigues JF, Duru G, Henry P, Lucas C, Pradalier A, Chazot G, Gaudin AF. Prevalence and description of chronic daily headache in the general population in France. Pain 2003;102:143-9.

Linton-Dahlof P, Linde M, Dahlof CGH. Withdrawal therapy improves chronic daily headache associated with long-term misuse of headache medication: a retrospective study. Cephalalgia 2000;20:658-62.

Lu SR, Fuh JL, Juang KD, Wang SJ. Repetitive intravenous prochlorperazine treatment of patients with refractory chronic daily headache. Headache 2000;40:724-9.

Lu SR, Fuh JL, Chen WT, Juang KD, Wang SJ. Chronic daily headache in Taipei, Taiwan: prevalence, follow-up and outcome predictors. Cephalalgia 2001;21:980-6.

Pini LA, Bigarelli M, Vitale G, Sternieri E. Headaches associated with chronic use of analgesics: a therapeutic approach. Headache 1996;36: 433-9.

Prencipe M, Casini AR, Ferretti C, Santini M, Pezzella F, Scaldaferri N, Culasso F. Prevalence of headache in an elderly population: attack frequency, disability, and use of medication. J Neurol Neurosurg Psychiatry 2001;70:377-81.

Pringsheim T, Howse D. In-patient treatment of chronic daily headache using dihydroergotamine: a long-term follow-up study. Can J Neurol Sci 1998;25:146-50.

Scher AI, Stewart WF, Liberman J, Lipton RB. Wolff Award 1998. Prevalence of frequent headache in a population sample. Headache 1998;38:497-506

Scher AI, Lipton RB, Stewart W. Risk factors for chronic daily headache. Curr Pain Headache Rep 2002;6:486-91.

Schnider P, Aull S, Baumgartner C, Marterer A, Wober C, Zeiler K, Wessely P. Long-term outcome of patients with headache and drug abuse after inpatient withdrawal: 5-year follow-up. Cephalalgia 1996; 16:481-5. discussion.

Wang SJ, Fuh JL, Lu SR, Liu CY, Hsu LC, Wang PN, Liu HC. Chronic daily headache in Chinese elderly: prevalence, risk factors, and biannual follow-up. Neurology 2000;(2000):314-9.

Zed PJ, Loewen PS, Robinson G. Medication-induced headache: overview and systematic review of therapeutic approaches. Ann Pharmacother 1999;33:61-72. 